\title{
EL MOTIVO LITERARIO DE LA BÚSQUEDA DEL PADRE EN LA NARRATIVA DE CARLOS PUJOL
}

\author{
Teresa Vallès-Botey \\ Universitat Internacional de Catalunya \\ Barcelona, España \\ tvalles@uic.es
}

RESUMEN / ABSTRACT

Mediante el análisis de cinco novelas del poeta, narrador, traductor y crítico Carlos Pujol (Barcelona, 1936-2012) se pone a prueba un modo de superar el problema terminológico y metodológico que lastra el estudio de motivos literarios como el de la búsqueda del padre, que autores de todas las épocas han recreado desde que Homero narró el viaje de Telémaco al encuentro de Ulises. Se abordan también otras cuestiones escurridizas como la jerarquía entre los motivos de una obra y la interrelación entre motivo, tema y género. Por otra parte, indagar la razón de la presencia recurrente de la búsqueda del padre en la narrativa de Pujol nos llevará a profundizar en la relación entre biografía y ficción según el pensamiento literario del escritor.

Palabras clave: motivo literario, búsqueda del padre, Telémaco, Carlos Pujol (1936-2012), pensamiento literario.

\section{THE LITERARY MOTIF OF THE SEARCH FOR THE FATHER IN CARLOS PUJOL'S NARRATIVE}

Through the analysis of five novels of poet, narrator, translator, and critic Carlos Pujol (Barcelona, 1936-2012), we intend to overcome a terminological and methodological problem that encumbers the study of literary motifs, such as the search for the father that has been treated by authors all periods, since Homer narrated Telemachus' journey to find Ulysses. Other elusive questions are also addressed, such as the hierarchy among the motifs of a given work and the interrelationship between motif, theme and genre. Approaching the recurrent use of the search for the father in Pujol's narrative will allow us to delve into the connection between biography and fiction according to the writer's literary ideas.

KEYWORDS: Literary motif, search for the father, Telemachus, Carlos Pujol (1936-2012), literary thoughts. 


\section{INTRODUCCIÓN ${ }^{1}$}

Los motivos literarios constituyen un elemento relevante del análisis de coincidencias y divergencias temáticas a nivel supranacional propio de la Literatura Comparada. Sin embargo, la anarquía terminológica que lastra este ámbito de la tematología (Naupert 20) genera no poca confusión y dificulta el consenso en la teoría y el análisis literario. ¿Qué entendemos por motivo literario? ¿En qué se diferencia de tema y de otros elementos recurrentes como símbolo o tópico? ¿Qué relación hay entre motivo y género narrativo? ¿Qué tipos de motivos se pueden distinguir y cómo se relacionan entre sí en una obra determinada?

Abordaremos estas y otras cuestiones a propósito del análisis del motivo de la búsqueda del padre, que en la tradición literaria tiene como referente el viaje de Telémaco tras el rastro de Ulises narrado en la Odisea y retomado por autores medievales, modernos y contemporáneos como María de Francia, Fénelon, Walter Scott y Dostoievski, por citar solo algunos ejemplos. En el ámbito de la literatura hispanoamericana contemporánea han recreado la búsqueda del progenitor escritores como Federico Campbell y Sandra Lorenzano y, en la literatura española, Carlos Pujol (1936-2012)2.

Efectivamente, diversas novelas de este poeta, narrador, crítico y traductor presentan una serie de elementos que se pueden asociar al motivo que funda Telémaco: un joven protagonista que padece el abandono de su progenitor, un viaje iniciático a la zaga de la figura paterna y el reencuentro como desenlace, que es también un reencuentro consigo mismo. Con todo, en la narrativa de Pujol estos elementos recurrentes aparecen de forma sutil y no constituyen un esquema argumental inalterable y reconocible a primera vista-como pone en evidencia el hecho de que no han sido hasta ahora apreciados por la crítica ${ }^{3}$.

Nos proponemos aquí analizar el motivo de la búsqueda del padre en las novelas de Carlos Pujol La sombra del tiempo (1981), Un viaje a España

Agradezco a Laureano Bonet y Ángela Navarro su atenta lectura de una versión previa de este trabajo.

Vid. en Vallès-Botey (Obras) las referencias a la obra completa de este polifacético y todavía poco estudiado autor a quien la revista Ínsula ha dedicado recientemente un monográfico (Ínsula 849, septiembre 2017). Sobre los otros autores mencionados, vid. Ruffinelli y González Luna.

Para una visión panorámica de la narrativa de Carlos Pujol, vid. Ródenas de Moya y Vallès-Botey (Bibliografía) para la bibliografía sobre este autor. 
(1983), Es otoño en Crimea (1985), Los días frágiles (2003) y Antes del invierno (2008), y abordar la caracterización de la búsqueda del padre en la tradición literaria y en las novelas de este autor, la tipología y jerarquía de los motivos de cada novela, la relación entre motivo y tema, y entre motivo y género novelístico. Por otra parte, se indaga la razón de la presencia recurrente de este elemento estructural en la narrativa de Pujol y se pone en relación dicha explicación con el pensamiento literario del autor sobre el vínculo entre vida, memoria y ficción.

Para ello, en primer lugar presentamos una propuesta operativa de delimitación conceptual del término motivo literario; en segundo lugar, se aborda la presencia y caracterización de la búsqueda del padre en la historia de la literatura. Finalmente, se analiza dicho motivo en las cinco novelas que son objeto de estudio y se examina su relación con los temas y el género de estas obras.

\section{EL MOTIVO LITERARIO COMO SITUACIÓN ESTEREOTIPADA Y RECURRENTE}

Es casi un lugar común lamentar que el término motivo literario adolece de imprecisión, pues la crítica lo ha utilizado con sentidos dispares e incluso incoherentes. Tras un detallado repaso de la evolución histórica del vocablo, Margery (19) ${ }^{4}$ llega a la conclusión de que

con el término 'motivo' la teoría y crítica literarias han significado indiscriminadamente elementos tales como el esquema básico de una situación concreta, el tema, el tipo -o cliché-, el símbolo fijo, el locus y hasta la imagen. En otras palabras, el 'motivo' ha llegado en literatura a constituir la denominación de cualquiera unidad de la textura significativa o formal de la obra literaria con la única condición de que ella posea una manifestación iterante ya en el plano individual,

\footnotetext{
El recorrido histórico de Margery abarca los primeros usos del término a finales del siglo XIX (Bedier, Polti), la Escuela finesa sobre el cuento folclórico (Aarne y Thompson, autores del famoso Motif-Index of Folk-Literature), los analistas rusos (Veselovskij, Volkov, Propp y Tomasevskij), la teoría literaria alemana de postguerra (Kayser) y aportaciones más recientes como las de Burke y Todorov, entre otras. Vanhelleputte, Klein y Márquez retoman el debate terminológico.
} 
generacional o diacrónico. Como resultado obvio, un elemento de estas características dista en mucho de ser efectivamente operativo en cualquier enfoque en el que él se inserte.

Ante esta situación de anarquía terminológica (Naupert 20), caben dos estrategias: o bien adoptar el término como un comodín casi universal -"any definition of the literary motif should be as broad as possible" (Wolpers 80)-; o bien restringir su alcance y fijar su relación con otros tipos de unidades (tema, tópico, símbolo, etc.), de modo que se eviten inexactitudes y vacilaciones terminológicas que -lamenta Naupert (20)- son un lastre del cual la tematología no ha sabido librarse.

De acuerdo con la segunda estrategia, optamos aquí por reservar el término motivo literario para designar la representación verbal de una situación relacional entre personajes - de la que interesa en primer lugar la estructuraque se percibe como típica o estereotipada (por ejemplo, 'el amor imposible') (Kayser; Margery) ${ }^{5}$. Este elemento estructural es un esquema abstracto que no está fijado ni concretado de manera exacta y que solo captamos cuando comparamos diversas obras y prescindimos de cualquier actualización concreta. Los motivos expresan situaciones típicas que se repiten y, si bien se inspiran en constantes antropológicas (Naupert 22; Wolpers 83), las representan de forma estereotipada, de modo que más que un reflejo de lo real, son una deformación convencional de éste (Erlich 344).

Así pues, motivo se asocia a situación y por situación se entiende el enunciado de un acontecimiento en el que participa al menos una actancia como sujeto u objeto (Margery 19). El vínculo con una situación específica permite distinguir el motivo ('el injusto destierro') del tema ('la injusticia', 'el poder', etc.) y evitar lo que Segre (347) considera una peligrosa tendencia del término motivo a colisiones sinonímicas con el tema. El solapamiento se produce cuando tema (theme) se utiliza de forma indiscriminada para designar theme-topic (por ejemplo, 'el amor paternofilial') y theme-motif ('la búsqueda del padre'), y es inevitable si se considera el grado de abstracción

5 Esta noción de motivo incluye lo que Wolpers (85) llama motivos de situaciones (Situationsmotive) y motivos de personajes (Figurenmotive). En cambio, lo que él designa como motivos basados en objetos, espacios o momentos utilizados como símbolos (como el espejo, el jardín y el alba) desde nuestra perspectiva no son propiamente motivos.

Delimitaremos con las comillas simples el nombre de los distintos motivos literarios, excepto el de la búsqueda del padre, que por ser el objeto de estudio es recurrente. 
como única diferencia entre tema y motivo -como asume por ejemplo Wolpers (91). Desde nuestra perspectiva, la diferencia entre temas como 'el amor paternofilial' o 'la nostalgia del padre' y el motivo de la búsqueda del padre no es solo que los temas tienen un mayor grado de generalización, sino que únicamente el motivo está vinculado a una situación estereotipada ${ }^{6}$. Mientras que las obras que recrean nuestro motivo tratan de alguna manera el tema de la 'nostalgia de padre', en cambio entre todas las que abordan este tema solo algunas representan la situación típica recurrente propia de dicho motivo?.

La relación entre los temas y motivos no es unidimensional. Por una parte, en obras como El Cid y La reivindicación del Conde don Julián, de Juan Goytisolo al tema de 'la injusticia' confluyen varios motivos ('la rebelión sofocada', 'el injusto destierro') (Margery 20). Por otra parte, un mismo motivo puede estar asociado a varios temas. El motivo 'la rebelión sofocada' -definido como "una colectividad que se alza unánimemente contra la injusticia es aplastada por la fuerza de los opresores"- está vinculado a temas como 'la injusticia', 'la rebelión' o 'la humildad oprimida' en obras como Fuenteovejuna, de Lope; Los tejedores, de Hauptmann o El mundo es ancho y ajeno, de Ciro Alegría (20). Desde este punto de vista, contrariamente a lo que defiende Rossiello (206), los motivos no se enlazan con los temas en una relación inferencial de causalidad ni el tema es -necesariamente-(como) una metonimia del motivo. Si bien se puede ver metonimia entre el tema 'la rebelión' y el motivo 'la rebelión sofocada', no la hay entre este motivo y temas como 'la injusticia' o 'el poder' a los que puede estar asociado en una obra determinada.

Queda por resolver la jerarquía entre los diversos motivos que concurren en una obra. De acuerdo con Margery (23), cabe distinguir los motivos principales (uno de los cuales es el conductor) ${ }^{8}$ y los motivos secundarios

6 Por la misma razón el motivo literario se distingue de otros elementos recurrentes como Leitmotiv (como una palabra o un color reiterado), símbolos (paloma blanca) o tópicos (carpe diem).

Así, ninguna de las tres novelas recientes sobre dicho tema que estudia Arbona Abascal adopta el motivo de la búsqueda del progenitor. Se trata de Ojos que no ven (2010), de J. A. González Sainz; Intemperie (2013), de Jesús Carrasco, y Retorno de un cruzado (2013), de José Jiménez Lozano.

De la argumentación y ejemplos que aporta Margery (23), se deduce claramente que en una obra puede haber más de un motivo principal (uno de los cuales será considerado el motivo conductor pues se le asigna una posición preponderante respecto a los demás). 
(que son expletivos con respecto a la trama). En el caso de Frankenstein o el Prometeo moderno, de Mary Shelly, concurren dos motivos principales: 'el extraño en su mundo' (motivo conductor de la novela, característico del romanticismo: "Un ser cuya índole psíquica o física es excepcional en un medio, resulta a causa de ello rechazado o incluso, sancionado") y 'el gólem' (que es otro motivo principal de la obra por su estrecho vínculo con la trama: "Un ser dotado de poder superior da origen a una criatura que a pesar de haber sido concebida como imagen de su hacedor, no alcanza tal condición") 9 .

Además de los principales y secundarios, Margery (28) define el motivo enmarcante, que tiene como rol servir de soporte -introductorio o de relaciónde la textura narrativa que aporta el motivo principal. Son motivos enmarcantes perceptibles a través de la tradición literaria 'el viaje', 'el recuento vital'10 $\mathrm{y}$ 'el objeto de posesión traspasada' ${ }^{11}$. En cuanto a 'el viaje', es enmarcante cuando coexiste junto a un motivo principal más específico como 'el injusto destierro' ( $E l$ Cid), 'el extraño en su mundo' (El Quijote)o 'la búsqueda del padre' (Los hijos del Capitán Grant, de Julio Verne). En cambio, es motivo principal en novelas de aventuras que no están configuradas por otro motivo más concreto (El viaje al continente, de Stevenson; Las aventuras de Arthur Gordon Pym, de Poe) (24). Así pues, la condición de enmarcante no es consustancial sino que el mismo motivo puede ser principal en unas obras y enmarcante en otras.

En general, puesto que la condición de principal (conductor o no), secundario o enmarcante no es una propiedad inherente al motivo sino relativa a una obra concreta (deducida del valor que se asigna al motivo en aquella historia), en rigor no se trata de tipos de motivos sino de funciones que desempeñan en una trama de acuerdo con una determinada interpretación.

Sin embargo, en otro momento menciona "la distinción entre [motivos] 'principales' -o 'conductores'- y 'secundarios"' (23), como si los principales fueran siempre conductores.

$9 \quad$ Este motivo puede reconocerse en obras como Las ruinas circulares, de Jorge Luis Borges, y Aura, de Carlos Fuertes. La denominación de 'el gólem' se basa en una expresión hebrea que denota a un autómata que imita la figura y los movimientos de un ser animado (Margery 21, 26).

10 Por ejemplo, La muerte de Artemio Cruz, de Carlos Fuentes, y Señas de identidad, de Juan Goytisolo.

11 El reloj, de Iván Turguenev, por ejemplo, se configura sobre la base de episodios unidos por un objeto que cambia sucesivamente de dueño. 


\section{EL MOTIVO DE LA BÚSQUEDA DEL PADRE EN LA TRADICIÓN LITERARIA}

La búsqueda del padre representa una situación estereotipada y recurrente que se puede definir como "un joven inexperto viaja en busca de su progenitor y con el (re)encuentro alcanza también una mayor comprensión de su identidad". A grandes rasgos, se distinguen los siguientes elementos nucleares del motivo: (i) el protagonista es un joven que padece el abandono de su progenitor y (ii) su deseo de un reencuentro paternofilial es el motor de (iii) un viaje exterior que es también (iv) un itinerario interior de maduración.

Frenzel (42-48) le dedica seis páginas en su Diccionario de motivos de la literatura universal y aporta numerosos ejemplos desde la antigüedad hasta el siglo $\mathrm{XX}^{12}$. Tiene su origen en la literatura indogermánica heroica (Persia, Grecia, Rusia, países germánicos...) y se consolida con el ciclo de leyendas de Ulises, con tres variaciones del mismo motivo. La más antigua aparece en la Odisea (s. VIII a. de C.) y narra la aventura de Telémaco, heredero legítimo de Ulises, quien preocupado por la situación de la casa paterna realiza un viaje por orden de Atenea para cerciorarse sobre el destino del padre, a quien finalmente encuentra cuando regresa.

Las cerca de cincuenta obras que menciona Frenzel ponen de manifiesto la fecundidad y variabilidad del motivo y cómo ha sido actualizado y renovado en cada época, tal como se aprecia en obras tan dispares como el Lai de Milón (1160) de María de Francia, Las aventuras de Telémaco (1699) de Fénelon, Redgountled (1824) de Walter Scott y El adolescente (1875) de Dostoievski. La búsqueda del padre unas veces es el motivo principal (como en la novela de Dostoiveski) y otras es un motivo secundario que inspira una subtrama (como en la Odisea, cuyo motivo principal es el 'viaje de retorno a casa').

Mención especial merece una obra que Frenzel no cita pero que tiene un significado singular para Carlos Pujol. Se trata de Kim (1901), novela de aventuras y espionaje del Premio Nobel de Literatura Joseph Radiar Quisling. En una entrevista, Pujol recuerda que se la regalaron cuando tenía ocho años

12 Como ejemplos del siglo XXI cabe citar las novelas La clave Morse (2001), de Federico Campbell, y Fuga en mí menor (2012), de Sandra Lorenzano (vid. Ruffinelli; González Luna), además de las dos últimas que analizaremos: Los días frágiles (2003) y Antes del invierno (2008), de Carlos Pujol. 
y que a lo largo de su vida la ha releído más de veinte veces, pues es un libro -afirma- que sigue deslumbrando y haciendo soñar.

Esa novela ... es arrebatadora y significativa. Con ella, la parte esencial de niñez que todos llevamos dentro se siente identificada. Narra la mayor aventura de mundo, la que convierte a un niño en hombre después de dejar atrás a los padres - estas historias siempre se inician con la obligada orfandad-y de buscar a tientas otros padres elegidos, que con el tiempo se abandonan o nos abandonan hasta llegar al hallazgo de uno mismo. Así sucede con el personaje de Kim, complementado - más que dividido- por dos búsquedas que parecen antagónicas: la espiritual del purificador Río de la Flecha, guiada por el viejo lama tibetano, y la tan prosaica del espionaje inglés conocido por “el Gran Juego" (Pujol, La aventura 29).

La búsqueda del padre es claramente el motivo principal de esta novela protagonizada por un joven huérfano que realiza un viaje iniciático por la India durante el cual entabla una entrañable relación con dos figuras paternales complementarias (un espiritual lama tibetano y un comerciante de caballos que lo introduce en el espionaje). No es poco el impacto de esta novela en la narrativa de Pujol, según su propio parecer:

Kim es el arquetipo de novela de aventuras, que para uno casi equivale a decir de la novela sin más. Seguramente es el origen de un prejuicio personal contra otras clases de novela (por ejemplo, de amor, de ideas o de costumbres), que ha hecho que todos mis libros cuenten eso, aventuras (Pujol, La aventura 29).

Sin duda Kim es el referente cercano del motivo literario que el autor barcelonés recrea, novela en la que, según Pujol, Kipling estaba dando la explicación mítica de sí mismo.

\section{EL MOTIVO DE LA BÚSQUEDA DEL PADRE EN LA NARRATIVA DE CARLOS PUJOL}

Tres de las cinco novelas que analizaremos forman parte de la primera etapa de la trayectoria narrativa de Carlos Pujol -La sombra del tiempo (1981), Un viaje a España (1983) y Es otoño en Crimea (1985) - y dos son de la primera década del siglo XXI: Los días frágiles (2003) y Antes del invierno 
(2008). Como tenue denominador común de estas novelas cabe destacar una ambientación histórica en situaciones políticas convulsas de los siglos XIX y $\mathrm{XX}$, y un estilo marcado por un narrador focalizado en un protagonista que manifiesta con ironía su nostalgia e incertidumbre y experimenta un proceso de transformación interior que lo lleva a un estadio superior de conformidad consigo mismo ${ }^{13}$.

La primera cuestión a resolver es la razón de la presencia tan recurrente de la búsqueda del padre en la narrativa de nuestro autor, que actualiza el motivo en su primera novela y lo retoma después una y otra vez. En este sentido, cabe preguntarse si también se refiere a él cuando afirma en una entrevista que un escritor como Baroja tiene un Leitmotiv constante que se nutre de su mundo interior y que puede pasar desapercibido al lector:

los escritores, los novelistas, suelen contar siempre la misma historia. Las novelas de Baroja parecen todas la misma ... y es que era su novela, la poetización imaginaria de algo que tenía dentro y ni podía ni sabía contar otra cosa.

Es en este sentido en el que hay que entender la parte propia del escritor y que solo conoce él, nadie más. ... El escritor puede repetir cien veces su propia historia sin que el lector se dé cuenta (Pujol, Hay muchos 35).

En enero de 2015 expuse esta cuestión en un seminario sobre Pujol y lamenté que quien realizó la entrevista citada no le preguntase cuál era $s u$ historia, la que quizá contaba de cien formas distintas. La mujer del escritor, que estaba presente, nos dio la clave cuando momentos después Dolors Massot la entrevistó ante los alumnos que asistían al seminario. La reproduzco aquí con su permiso. Escuetamente, sin entrar en detalles, Marta Lagarriga contó que Pujol había tenido desde joven una relación muy dolorosa y conflictiva con su padre y que por eso es recurrente en su obra la búsqueda de la figura paterna.

13 El desenlace de sus novelas contrasta con el de una recreación del mismo motivo literario que Pujol (La búsqueda del padre) había reseñado en 1977: Los bulevares periféricos del Nobel de Literatura Patrick Modiano, en la que Pujol subraya la paradójica "figura del hijo obstinado que no renuncia a la búsqueda, aun sabiendo que en la medida en que consiga su propósito su meta ha de ser la decepción". 
Este enclave autobiográfico del motivo nos lleva a un aspecto del pensamiento estético del autor que tiene que ver con la materia prima de la literatura."Se escribe -afirma Pujol (Cuadernos de escritura 133)- sobre recuerdos e imaginaciones, no con lo que se ve", pues la literatura no trata sobre "lo que me ha pasado" - 'Lo que la gente entiende por 'pasar' nunca es literatura" (25). La literatura no se nutre tanto de los hechos biográficos del escritor como de su mundo interior, de los recuerdos y fantasmas que esos episodios han suscitado. Pujol relativiza el peso de los acontecimientos y subraya el papel de la memoria y la imaginación cuando le preguntan si es cierto que un escritor siempre se refleja, de alguna manera, en sus novelas:

Sí. Es muy difícil salirse de uno mismo. A menudo la gente lo interpreta como hechos concretos vividos por ti o por amigos y en algunos casos es así, pero el escritor no es el que sólo sabe contar una historia que ha vivido. Yo te puedo decir que jamás he contado nada de lo que me ha pasado; no encontrarás en mis libros ninguna historia autobiográfica, no tengo ningún interés en ello. Lo que se reflejan son fantasmas, fantasmas personales, obsesiones, recuerdos, vestidos aderezados, disfrazados, exagerados, poetizados... pero en el fondo, vuelves la vista atrás y ves toda la trama de las fantasías, sueños, frustraciones, traumas, todo son recuerdos. Es decir, no la vida biográfica vista desde el exterior, sino la propia vida interior que, sin que uno se lo proponga, acaba saliendo al exterior (Pujol, Hay muchos 35).

Así, pues, en la narrativa de Pujol el motivo de la búsqueda del padre surge de la poetización de una circunstancia personal que se refleja en una obra literaria básicamente alimentada por el mundo interior del escritor, de su memoria e imaginación. Veamos cómo reelabora el motivo en cada novela para después comparar su función en todas ellas.

\section{LA SOMBRA DEL TIEMPO (1981)}

Carlos Pujol inicia su trayectoria narrativa en 1981 con La sombra del tiempo. Está entonces en plena madurez vital -cuarenta y cinco años, casado y con cuatro hijos-, trabaja en la editorial Planeta desde 1963, ha publicado diversos ensayos sobre literatura francesa -fruto de su dedicación a la docencia universitaria, que por entonces ha dejado-, así como traducciones 
(Balzac, Voltaire, Lainé Pascal, Defoe, Hemingway, Joan Sales) y artículos de crítica literaria (La Vanguardia, El Ciervo, Opinión). Tras esta primera novela, se sucederán los títulos hasta publicar unas cincuenta obras de creación (narrativa, poesía, aforismos, ensayo) y un centenar de traducciones (Vallès-Botey, Obras).

Protagoniza esta primera novela Clara, una joven aristócrata que -huyendo del Terror de la Francia revolucionaria- se establece en Roma en vísperas de la llegada de las tropas francesas que en 1799 pondrá fin al Antiguo Régimen. Cuando años después rememora sus primeros meses en Roma, recuerda que eligió ese destino por el deseo de reencontrarse con la ciudad que había soñado de niña, cuando su padre regresaba de viaje y le mostraba las Vedute di Roma de los grabados de Piranesi.

¿Por qué Roma? ¿Por qué no estaba en Madrid o en Milán, donde tía Stéphanie tenía también parientes y amigos que hubieran podido acogerme? ... Cuando era niña mi padre me hablaba de Roma, abría un cartapacio con estampas de antigüedades de Roma, recitaba una letanía de nombres de lugar que sonaban a música y evocaba la leyenda y la historia con latines, un poco de Virgilio. ...

Mi padre había muerto, quedé sola en la vida, luego me casé, enviudé a los pocos meses, Francia se había convertido en un infierno del que era necesario huir. ... dije que tenía decidido ir a Roma; para hacer frente a lo que recordaba de mi niñez, las estampas, mi padre, recuperar no lo que acababa de perder en Francia, sino lo que llevaba en la memoria, medio borroso, extraviado entre recuerdos que ahora eran mi único tesoro (Pujol, La sombra del tiempo 17) ${ }^{14}$.

La obra refleja un proceso de recuento vital en el que la efigie paterna aparece repetidamente $(17,23,28,37,115,118,197)$, siempre ligada al recuerdo de sus explicaciones ante los grabados y al deseo no confesado de un reencuentro en la ciudad que él le había prometido mostrar:

mi padre mostrándome aquellas vistas de Roma, comentando los detalles, dándome explicaciones históricas y artísticas, diciéndome

14 Las citas corresponden a la última edición de la novela (Sevilla: Fundación José Manuel Lara, 2016). 
que algún día los dos visitaríamos aquellos lugares, y que él entonces iba a servirme de guía (115).

La evolución vital de la protagonista se realiza de la mano del recuerdo paterno y pasa por aceptar dolorosamente que su Roma es un sueño infantil que no se corresponde con la realidad de la ciudad que ahora ha conocido, pues al crecer ha "trocado por fin la niñez por la edad adulta, el sueño de Roma por la Roma de veras" (127).

¿Qué función tiene en esta novela de ambientación histórica el motivo de la búsqueda del padre? Se materializa en un viaje para recuperar el recuerdo paterno y se resuelve en un proceso de maduración y configuración de la propia identidad. La búsqueda del padre es el motivo principal de la narración, tanto por su peso dentro de la trama como por la ligazón significativa con la temática. Aparece entrelazado con diversos temas ('la nostalgia del padre', 'identidad y memoria', 'el paso del tiempo') y con el motivo 'el recuento vital', que es motivo enmarcante.

\section{ES OTOÑO EN CRIMEA (1985)}

El protagonista de esta novela es otro joven huérfano, al que llaman Charlie (o Chawlie) y que parece sacado de una novela de Dickens. Comienza el relato con la constatación de la ignorancia que conlleva su temprana orfandad.

Cuando murió mi padre yo no sabía qué hacíamos en Londres, y nunca llegué a saberlo. Hay cosas que pertenecen a lo más oscuro de nuestra vida, y que son sin embargo lo único que puede explicarla, y esos secretos rehúyen nuestra curiosidad (Pujol, Es otoño en Crimea 7).

Las lagunas sobre su identidad están asociadas a vagos recuerdos de la figura paterna -de quien no sabe siquiera la nacionalidad- $y$ a incertidumbres sobre lo que significa la paternidad.

Si decía Yo, era otro el que estaba hablando, un niño que dialogaba en la casa de Cindy Lane con aquel hombre de mirar melancólico al que estaba acostumbrado a llamar Padre (81).

A lo largo de la novela se adivina en Charlie el anhelo de trabar una relación de filiación y hay diversos personajes que representan un papel paternal, 
a veces caricaturizado y poco ejemplar. El más evidente es Mr. Reid, un poeta histriónico y alcohólico que recoge de la calle a Charlie y se lo lleva como ayudante a la Guerra de Crimea, en un viaje que para el joven será iniciático. En un momento dado, Mr. Reid afirma solemnemente que nombra al huérfano Stewart adoptivo suyo (52), pero más tarde le recrimina duramente su ingenuidad:

¿Me has tomado por tu padre o algo parecido? Te juro que me das lástima, Chawlie; eres débil y crédulo, necesitas creer en algo, y me has elegido precisamente a mí (190-191).

En el desenlace de la novela, Charlie decide alejarse del mal padre que ha sido para él Mr. Reid y acepta la ayuda y los consejos de dos personajes que ha conocido en Crimea: un enigmático y entrañable espía (en realidad, el general Prim) y el capitán Mercadal, con quien establece una relación paternofilial. El protagonista huye de la guerra a bordo del barco de Mercadal y gracias a él descubre un dato relevante sobre su identidad y su origen: su lengua materna es el catalán.

Es otoño en Crimea es una novela iniciática y de aventuras, en la cual 'el viaje' desempeña la función de motivo enmarcante (como es habitual en las novelas de aventuras) y la búsqueda del padre es el motivo principal. Tanto en La sombra del tiempo como en Es otoño en Crimea los protagonistas viven su orfandad como una dolorosa forma de soledad y desconocimiento de uno mismo que los impele a emprender viajes y desear encuentros humanos. En ambos casos la mirada melancólica del narrador en primera persona se enternece en un desenlace feliz que, por imprevisto, logra sorprender al lector.

\section{UN VIAJE A ESPAÑA (1983)}

En Un viaje a España, publicada dos años después de La sombra del tiempo, Pujol desmitifica la búsqueda del hijo con una parodia que, en una breve aparición como personaje de la novela, Balzac sugiere titular "El padre pródigo o En busca del padre perdido" (Pujol, Un viaje a España 237) ${ }^{15}$. El motivo

15 Como señala Hutcheon (1985), la parodia es una forma de imitación con inversión irónica, una transcontextualización irónica. Ironía e imitación con distancia crítica son, pues, los dos elementos característicos de la parodia, que puede tener muy diversas intenciones: 
aparece transformado hasta convertirse en una parodia que desdramatiza cada uno de los elementos que lo caracterizan. Por una parte, Don Emilio, padre del protagonista, ha desaparecido voluntariamente y su hijo está empeñado en hacerle volver a casa, como haría un progenitor con un vástago calavera. Por otra parte, el protagonista ni es huérfano ni está desamparado, pues es un próspero banquero parisino llamado René de Giben, que contrata a VautrenVidoq -el mítico personaje balzaquiano- para que le acompañe a España a localizar a Don Emilio y traerlo de vuelta.

Quiero hacer que mi padre vuelva a París, y usted es el único que puede ayudarme a conseguirlo. No será fácil, sepa que no ha perdido la cabeza por una mujer, mucho peor que eso, la ha perdido por una quimera $(24)^{16}$.

Como se ve, las razones de la desaparición es otro de los elementos que Pujol desmitifica. El móvil del viaje paterno no es ya la legendaria Guerra de Troya, sino una quimera, el deseo de sentirse todavía joven e idealista uniéndose a la causa de la guerra carlista, contienda que se presenta con sarcasmo:

-¿Qué sabe de esa guerra de España? -preguntó.

Se encogió de hombros, como quien se ve obligado a explicar algo evidente.

- De vez en cuando los españoles necesitan matarse entre sí -dijo (29).

Tampoco se libra de la mirada burlona la figura del antes temido y brutal Vautren, que Pujol recrea cuando está tomando dolorosa conciencia de que se ha hecho mayor. Así, el acompañante del hijo ya no es Atenea bajo la apariencia del sabio Méntor, sino un antiguo criminal a quien se contrata como detective y que está lleno de dudas sobre su identidad. Un desconcertado y melancólico Vautren admite que

homenajear, divertir, ridiculizar, menospreciar, etc. En el caso de Pujol, la parodia del motivo de la búsqueda del padre tiene una función lúdica y, como su ironía, sintoniza con su estrategia narrativa de decir y ocultar a la vez: "Hacer libros divertidos pero secretos, ésta es la fórmula" (Cuadernos de escritura 49).

16 Las citas corresponden a la segunda edición de la novela (Pamplona: Pamiela, 1993). 
no conseguía librarse de unas cuantas preguntas que giraban vertiginosamente en su cerebro como un carrusel. ¿Qué se ha hecho de Vautrin? ¿Soy yo? El Mec, como me llama mi gente, el Dab, el Jefe que hace temblar a todos. Vautrin ha envejecido y es un león amansado por la ternura (31).

Vautren aceptará el caso para tratar de vencer su propia desazón, en un viaje que en lugar de propiciar el paso a la edad adulta -como en el clásico itinerario iniciático- se emprende con el deseo de permanecer en ella y resistirse a envejecer: "volver a ser lo que fui al menos una vez más" (14). En su homenaje a Balzac, Carlos Pujol ofrece una visión humanizada de Vautren y hace patentes sus debilidades e incertidumbres; algo parecido hará nuestro autor con Sherlock Holmes en la novela Los secretos de San Gervasio (1994), donde un humanizado Holmes tiene que admitir el fracaso de su hasta entonces invencible y todopoderosa lógica.

El desenlace del relato propicia un reencuentro entre padre e hijo en el momento más inesperado y se resuelve también de forma irónica, pues el hijo-que ha encontrado un nuevo amor- se niega a regresar. Un viaje a España es una novela de aventuras con 'el viaje' como motivo enmarcante y la búsqueda del padre como motivo principal (eso sí, parodiado). Aborda temas tales como identidad y memoria, el sentimiento de fracaso vital y el deseo de recuperar la juventud y el tiempo perdidos.

\section{LOS DÍAS FRÁGILES (2003)}

La lista de protagonistas huérfanos o de padre desaparecido se alarga con Los dias frágiles (2003), que protagoniza un adolescente español que vive en París con su tía Henriette adonde fue enviado por sus padres cuando comenzó la Guerra Civil Española. Máxime, que en realidad se llama Paco, se siente abandonado por sus progenitores. Lamenta que una vez en París,

recibí un par de postales y llegaron dos o tres giros. Nada más. Los dos se diluyeron en la guerra, supongo que cada uno en un bando.... Quizás habían muerto o quizá no. Es posible que tuvieran otra vida en la que yo ya no cupiese (Pujol, Los días frágiles 16).

También en este caso el protagonista realiza un itinerario iniciático-tres días yendo de un lado a otro por París en vísperas de la entrada de los nazis-, 
pero hay que señalar que la obra no cumple uno de los elementos nucleares del motivo, pues el viaje no está impulsado por el deseo de un reencuentro con sus progenitores.

Casi no me acordaba de cómo eran, mejor dicho, no quería acordarme. Madrid era una puerta cerrada que prefería no abrir porque estaba seguro de que daba a algún lugar espantosamente cruel, insoportable, ruidoso (14).

En Los días frágiles el sentimiento de orfandad es una circunstancia del protagonista pero no constituye el motor de la acción; la trama no avanza al encuentro de la figura paterna, sino según el esquema de la novela de aventuras, de enredos y de espías. De acuerdo con esto, cabe considerar 'el viaje' el motivo principal, mientras que el sentimiento de orfandad es solo un subtema ${ }^{17}$. Si bien descartamos esta novela como actualización del motivo de la búsqueda del padre, su análisis ha servido para comprobar la operatividad de los conceptos teóricos adoptados.

\section{ANTES DEL INVIERNO (2008)}

Mención especial merece Antes del invierno (2008), novela de espías en la que Pujol reescribe la búsqueda del padre para darle la vuelta mediante una inversión irónica de sus elementos: en esta parodia del motivo literario será el progenitor quien tenga la iniciativa de salir en busca de su vástago y lo hará sobre todo porque necesita su ayuda. La ironía, que está presente en la narrativa pujoliana desde la primera novela, se acentúa visiblemente en las de la última década, de modo que no hay escena o diálogo que no esté empapado de una mirada irónica y desmitificadora ${ }^{18}$.

17 También es huérfano el protagonista de El teatro de la guerra, novela de espías en clave irónica protagonizada por un militar norteamericano destinado a Alemania al final de la Segunda Guerra Mundial. En cuanto acaba el conflicto armado viaja a un pequeño pueblo alemán con el deseo - que no logrará satisfacer- de conocer sus orígenes familiares y superar, dice, cierto malestar personal.

18 A la espera de un estudio sobre la ironía en la narrativa de Pujol, cabe apuntar que enlaza con diversos aspectos de su pensamiento literario: la concepción lúdica de la novela, la voluntad de mostrar verdades ocultas bajo las apariencias, la estrategia de decir sin decir 
Los cambios en el motivo se hacen notar enseguida, pues el reencuentro paternofilial se produce al comienzo de la novela $-\mathrm{y}$ no tras superar largas pruebas y penurias- y será el inicio de un progresivo acercamiento afectivo, que es a lo que tiende toda la trama. Este primer cara a cara ocurre cuando, tras años de vivir en Londres y sin contacto alguno, don Emilio aparece de improviso en el despacho oficial de su hijo Gonzalo en Barcelona. Comienza así la novela:

- ¿Sabes?, es como si salieras de la nada.

No me ofendí ni protesté, quizá fuese una buena descripción de mi vida de entonces, no estaba mal aquello de compararme con un aparecido. Un fantasma perplejo y desastrado del que ya nadie se acordaba, y que de pronto hacía acto de presencia viniendo del más allá como la sombra del padre de Hamlet (Pujol, Antes del invierno 9).

Con humor y huyendo de todo dramatismo, don Emilio se siente identificado con el fantasma del padre de Hamlet (pero sin deseo de venganza, matiza). La figura paterna ya no es un héroe trágico condenado a vagar por los dioses, sino un pobre fantasma "perplejo y desastrado". Más adelante se insiste en la identificación del padre con un fantasma cuando se alude a otro reencuentro mítico, el de Eneas y su padre Anquises en los Campos Elíseos, donde "el poeta dialoga con la sombra de su padre. El padre no es más que eso, una sombra" (49), dirá don Emilio.

Años atrás, don Emilio y Julia, su mujer, habían dejado Madrid y se habían refugiado en Londres para huir de la Guerra Civil, perdiendo del todo el contacto con su hijo, hasta el punto de no saber siquiera si estaba vivo. En Inglaterra, Julia abandona a su marido por otro hombre y él decide escapar de las bombas que caen sobre Londres (es la Segunda Guerra Mundial) y volver a España. Será entonces cuando busque a su hijo, de quien tiene noticia gracias, no a la poesía épica que en la Odisea transmite las hazañas de los héroes, sino a una revista de sociedad en la que aparece la fotografía de Gonzalo y la leyenda "poeta de la Falange".

Mientras Gonzalo, desde la posición de poder que le da su empleo oficial, hace gestiones para arreglar los papeles de su padre ante la policía, don Emilio se ve envuelto en una intriga de espías llena de muertes absurdas y confiesa

sugiriendo sin dar lecciones, el escepticismo ante toda pretensión de ver el mundo desde una sola perspectiva, etc. 
que tiene "la impresión de que habíamos intercambiado los papeles, ahora era yo quien debía dar explicaciones, como él cuando entregaba las notas de la escuela" (9). Más adelante, cuando Gonzalo constata la miserable pensión donde se aloja su padre, le propone que se vaya a vivir con él. Don Emilio apenas se resiste y su hijo se apresura a desdramatizar la situación poniendo como única condición una petición intrascendente.

-[Don Emilio] Oye, tú tienes tu vida...

-[Gonzalo] Lo malo es que tengo muchas vidas a la vez, y todas están terminando mal. Sólo te pido una cosa: Que te quites esa horrible corbata.

...Él me rescataba de la pensión Malvarrosa, pero yo tenía la vaga sospecha de que era él quien necesitaba que yo le salvase de no se sabe qué, de algún callejón sin salida que le había hecho recordar que tenía un padre (161).

Antes del invierno es una novela de espías (eso sí, de espías que citan versos de Browning) en la que Pujol inserta esta parodia irónica del motivo de la búsqueda del padre (que es el motivo principal): una "búsqueda del hijo" por parte de un padre ya maduro y con un doloroso sentimiento de fracaso vital. La trama se resuelve con un rescate mutuo y el triunfo del amor paternofilial. Es el desenlace feliz que anhela quizá todo hijo abandonado: ver de pronto aparecer a su padre, restañar las heridas del pasado y hacer frente al futuro con esperanza.

\section{ANÁLISIS COMPARADO DE LAS NOVELAS}

Todo hace pensar que Pujol recrea y transforma deliberadamente el motivo de la búsqueda del padre hasta hacer que la aparición recurrente de este elemento estructural pase desapercibida al lector. Como decía él a propósito de otro autor, el escritor puede repetir cien veces su propia historia sin que el lector se dé cuenta (Pujol, Hay muchos).

La variabilidad de este motivo en las novelas analizadas se puede ilustrar comparando sus elementos nucleares (v. Fig. 1): (i) el protagonista es un joven que padece el abandono paterno y (ii) su deseo de un reencuentro paternofilial es el motor de (iii) un viaje exterior y (iv) un itinerario interior de maduración. 


\begin{tabular}{lcccc}
\hline & $\begin{array}{c}\text { Perfil } \\
\text { protagonista }\end{array}$ & $\begin{array}{c}\text { Deseo } \\
\text { reencuentro }\end{array}$ & $\begin{array}{c}\text { Viaje } \\
\text { exterior }\end{array}$ & $\begin{array}{c}\text { Viaje } \\
\text { interior }\end{array}$ \\
\hline La sombra del tiempo (1981) & $\checkmark$ & $\checkmark$ & $(\checkmark)$ & $\checkmark$ \\
Viaje a España $(1983)$ & $\mathbf{x}$ & $\checkmark$ & $\checkmark$ & $\checkmark$ \\
Es otoño en Crimea (1985) & $\checkmark$ & $\checkmark$ & $\checkmark$ & $\checkmark$ \\
Los días frágiles $(2003)$ & $\checkmark$ & $\mathbf{x}$ & $(\checkmark)$ & $\checkmark$ \\
Antes del invierno $(2008)$ & $\mathbf{x}$ & $\checkmark$ & $(\checkmark)$ & $\checkmark$ \\
\hline
\end{tabular}

Fig. 1 Elementos nucleares del motivo de la búsqueda del padre

Dos de las novelas adoptan plenamente los elementos característicos de este motivo (La sombra del tiempo, Es otoño en Crimea). En cambio, el autor prescinde del perfil tradicional del protagonista como "joven desamparado" cuando reescribe y transforma el motivo mediante la parodia y la ironía (Viaje a España, Antes del invierno). La ausencia de un deseo de reencuentro como motor del recorrido del huérfano que protagoniza Los días frágiles nos ha llevado a descartar que esta novela de aventuras y espionaje contenga el motivo de la búsqueda del padre. Según esta interpretación, el anhelo de un reencuentro sería una condición necesaria, mientras que la transgresión del perfil prototípico del protagonista sería un ejemplo de libre reelaboración del motivo.

En cuanto al viaje exterior, se concreta unas veces en el clásico itinerario por el extranjero, tal como hizo Telémaco (Viaje a España, Es otoño en Crimea), mientras que en las otras obras es un recorrido por una ciudad desconocida para el protagonista; en ambos casos el entorno está por descubrir. El viaje interior está siempre presente y parece inherente al género novelístico tal y como lo concibe Carlos Pujol.

La función y la relevancia de la búsqueda del padre en cada novela hay que dilucidarla viendo su relación con otros motivos de la obra, y con los temas y el género narrativo. Se trata de novelas de género híbrido, con mesurada proporción (distinta en cada caso) de elementos de novela de ambientación histórica, de aventuras, iniciática, de intriga y de espías. Presentan una temática diversa, con cuestiones de fondo predominantes como 'la nostalgia del padre', 'identidad y memoria', y 'el paso del tiempo' -que son temas que el esquema argumental propio de la búsqueda del padre invita a abordar. 


\begin{tabular}{|c|c|c|c|c|}
\hline & $\begin{array}{l}\text { Principal } \\
\text { conductor }\end{array}$ & $\begin{array}{c}\text { Principal } \\
\text { no conductor }\end{array}$ & Enmarcante & Temas principales \\
\hline $\begin{array}{l}\text { La sombra del } \\
\text { tiempo }\end{array}$ & $\begin{array}{l}\text { 'búsqueda } \\
\text { del padre' }\end{array}$ & & $\begin{array}{l}\text { 'recuento } \\
\text { vital' }\end{array}$ & $\begin{array}{l}\text { identidad y } \\
\text { memoria, paso del } \\
\text { tiempo, fracaso y } \\
\text { poder }\end{array}$ \\
\hline Viaje a España & $\begin{array}{l}\text { 'búsqueda } \\
\text { del padre' }\end{array}$ & & 'el viaje' & $\begin{array}{l}\text { identidad, } \\
\text { sentimiento } \\
\text { fracaso vital, } \\
\text { deseo de recuperar } \\
\text { la juventud }\end{array}$ \\
\hline $\begin{array}{l}\text { Es otoño en } \\
\text { Crimea }\end{array}$ & $\begin{array}{l}\text { 'búsqueda } \\
\text { del padre' }\end{array}$ & $\begin{array}{l}\text { 'formación } \\
\text { interior' }\end{array}$ & 'el viaje' & $\begin{array}{l}\text { identidad personal, } \\
\text { gloria vana del } \\
\text { belicismo }\end{array}$ \\
\hline Los días frágiles & 'el viaje' & & & $\begin{array}{l}\text { identidad, paso del } \\
\text { tiempo }\end{array}$ \\
\hline $\begin{array}{l}\text { Antes del } \\
\text { invierno }\end{array}$ & $\begin{array}{l}\text { 'búsqueda } \\
\text { del padre' }\end{array}$ & & & $\begin{array}{l}\text { identidad, } \\
\text { sentimiento } \\
\text { fracaso vital, } \\
\text { triunfo del amor } \\
\text { paternofilial }\end{array}$ \\
\hline
\end{tabular}

Fig. 2 Motivos literarios y temas principales

Teniendo en cuenta esta interdependencia semántica entre motivos, temas y género de cada obra, entendemos que La sombra del tiempo es novela iniciática de ambientación histórica, con 'identidad y memoria' como tema central, la búsqueda del padre como motivo principal y 'el recuento vital' como motivo enmarcante. Por su parte, Es otoño en Crimea y Viaje a España son novelas de aventuras y de ambientación histórica, en las que 'el viaje' es el motivo enmarcante y la búsqueda paterna, el motivo principal (parodiado en la segunda de ellas), pues ambas tienen como motor de la acción la necesidad de (re)establecer la relación paterna. Finalmente, Antes del invierno es novela de espías que -como en Kim de Kipling-entremezcla el espionaje y el deseo de un encuentro paternofilial; la búsqueda es motivo conductor, aunque parodiado, pues es el padre quien va tras del hijo. 


\section{CONCLUSIONES}

Entendemos el motivo de la búsqueda del padre como la representación literaria de la situación estereotipada y recurrente de "un joven inexperto viaja en busca de su progenitor y con el (re)encuentro alcanza también una mayor comprensión de su propia identidad". Al definir motivo como una situación típica que se repite, se evita el solapamiento con la noción más abstracta de tema o con otros elementos recurrentes (símbolo, tópico, etc.). En cuanto a la jerarquía entre los motivos literarios de una obra, se resuelve precisando si son enmarcantes, principales (conductores o no) y secundarios -categorización que establece la función de un motivo en un relato determinado.

En cada novela, los motivos, los temas y el género construyen una unidad de sentido que hay que interpretar globalmente para asignar a cada uno su función y relevancia. Esta unidad explica su ligazón recurrente. Es reiterada, por ejemplo, la asociación del motivo 'el viaje' con el género de novela de aventuras y del motivo 'la formación interior' con la novela iniciática, así como la relación jerárquica entre 'el viaje' (como motivo enmarcante) y la búsqueda del padre (motivo principal). También es frecuente la concurrencia de la búsqueda del progenitor con temas como 'identidad y memoria' y 'el paso del tiempo', que pueden tener muy diversa relevancia en cada obra.

Mediante el estudio de nuestro motivo literario, en las novelas de Carlos Pujol hemos seguido el rastro de este hilo conductor de su narrativa, que tiene un tenue anclaje autobiográfico. De acuerdo con su poética, la realidad vivida por el autor tiene en la literatura una relevancia indirecta y muy relativa, pues solo es significativa en la medida en que ha dado origen a recuerdos, sueños y fantasías que -estos, sí- son materia prima de la ficción. La relación entre lo biográfico y lo literario se resuelve asumiendo con Pujol que, por una parte, el único tema es uno mismo, deformado y manifiesto como en una caricatura (Pujol, Cuadernos de escritura 20), y subrayando, por otra parte, que no se puede escribir sobre lo que se está viendo, sino solo sobre lo que se recuerda o se sueña (26).

Carlos Pujol recrea con gran libertad la búsqueda del padre, motivo que está especialmente presente en su primera etapa narrativa, con tres novelas de ambientación histórica - La sombra del tiempo, Un viaje a España y Es otoño en Crimea, la segunda de las cuales es una parodia de dicho motivo. Años más tarde, Pujol retoma la temática del sentimiento de orfandad en Los días frágiles y Antes del invierno. En esta última invierte el motivo para narrar una búsqueda del hijo y parece cerrar felizmente el ciclo que ha comenzado 
en su primera novela, pues el difícil reencuentro de la protagonista de $L a$ sombra del tiempo con el recuerdo de su progenitor, se transfigura en una sorprendente pero grata aparición del padre -cual fantasma del rey Hamlety en el rescate mutuo del padre y el hijo. Entre bromas y veras, Pujol hace realidad (literaria) el sueño de quien sufre la ausencia del ideal paterno.

\section{BIBLIOGRAFÍA}

Arbona Abascal, Guadalupe. "Los nuevos telémacos en la narrativa española reciente". Nuevas formas del mito: una metodología interdisciplinar. Ed. José Manuel Losada. Berlín: Logos Verlag, 2015. 133-146.

Erlich, Victor. El formalismo ruso. Barcelona: Seix Barral, 1974 [1969].

Frenzel, Elisabeth. Diccionario de motivos de la literatura universal. Madrid: Gredos, 1980.

González Luna, Ana María. "Exilio y búsqueda del padre en Fuga en mi menor de Sandra Lorenzano". Altre Modernità: Rivista di studi letterari e culturali 2 (2014): 79-92.

Hutcheon, Linda. A Theory of Parody: The Teachings of Twentieth Century Art Forms. New York: Methuen, 1985.

Kayser, Wolfgang. Interpretación y análisis de la obra literaria, 4a ed. Madrid: Gredos, 1970.

Klein, Holger. "Autum Poems: Reflections on Theme as Tertium Comparationis". The Return of Thematic Criticism. Ed. Werner Sollors. Cambridge: Harvard University Press, 1993. 146-160.

Margery, Enrique. "Sobre el 'motivo literario"”. Filología y Lingüística 8/1-2 (1982): 3-26.

Márquez, Miguel Á. “Tema, motivo y tópico. Una propuesta terminológica”. Exemplaria 6 (2002): 251-256.

Naupert, Cristina. Tematología y comparatismo literario. Madrid: Arco Libros, 2003.

Pujol, Carlos. Antes del invierno. Palencia: Menoscuarto, 2008. Cuadernos de escritura. Valencia: Pre-Textos, 2009. El teatro de la guerra. Palencia: Menoscuarto, 2009. Es otoño en Crimea. Barcelona: Plaza y Janés, 1985.

“"Hay muchos escritores chiflados"”. Entr. Montserrat Tapias. Diario de Tarragona 30 octubre 1994: 35 . 2001: 29 . "La aventura de abandonar la niñez". Entr. Xavi Ayén. La Vanguardia 31, agosto "La búsqueda del padre". Opinión 50. 16 set. 1977: 48. La sombra del tiempo. Barcelona: Planeta, 1981. La sombra del tiempo. 3르 ed. Sevilla: Fundación José Manuel Lara, 2016. Los dias frágiles. Barcelona: Edhasa, 2003. 
Un viaje a España. Barcelona: Plaza y Janés, 1983.

Un viaje a España. 2a ed. Pamplona: Pamiela, 1993.

Ródenas de Moya, Domingo. “Carlos Pujol, novelista”. Ínsula 849 (2017): 17-21.

Rossiello, Leonardo. "Tres versiones del motivo del ladrón sorprendido. Un estudio comparativo en relatos de Allende, García Márquez y Benedetti”. Studia Neophilologica 87 (2015): 202-217.

Ruffinelli, Jorge. "Telémaco en América Latina. Notas sobre la búsqueda del padre en cine y literatura". Revista Iberoamericana 199 (2002): 441-57.

Segre, Cesare. Principios de análisis del texto literario. Barcelona: Crítica, 1985.

Vanhelleputte, Michel. "The Concept of Motif in Literature: A Terminological Study". The Return of Thematic Criticism. Ed. Werner Sollors. Cambridge: Harvard University Press, 1993. 92-105.

Vallès-Botey, Teresa. "Obras de creación y traducciones de Carlos Pujol”. Ínsula 849 (2017): 44-49.

Vallès-Botey, Teresa. "Bibliografía sobre Carlos Pujol”. Ínsula 849 (2017): 50-55.

Wolpers, Theodor. "Motif as Structural Content Units and 'Concrete Universals"'. The Return of Thematic Criticism. Ed. Werner Sollors. Cambridge: Harvard University Press, 1993. 80-91. 